\title{
Cigarette smoking and smoking cessation in relation to risk of rheumatoid arthritis in women
}

\author{
Daniela Di Giuseppe ${ }^{1 *}$, Nicola Orsini ${ }^{1}$, Lars Alfredsson², Johan Askling ${ }^{3}$ and Alicja Wolk ${ }^{1}$
}

\begin{abstract}
Introduction: Whereas the overall association between smoking and rheumatoid arthritis (RA) must be regarded as established, considerably less is known about how much smoking is needed to increase the risk of RA, that is, the effect of smoking intensity, duration and cessation.

Methods: The Swedish Mammography Cohort, including 34,101 women aged 54 to 89 years, was followed up from January 1, 2003 through December 31, 2010 (219 RA cases identified). Relative risks (RR) and their 95\% confidence intervals $(\mathrm{Cl})$ were estimated as rate ratios using Cox proportional hazards model.
\end{abstract}

Results: There was a statistically significant association between smoking intensity (RR comparing 1 to 7 cigarettes/ day vs never smoking 2.31 ( $95 \% \mathrm{Cl}: 1.59,3.36)$ ) as well as duration of smoking (comparing 1 to 25 years vs never smoking RR $=1.60(95 \% \mathrm{Cl}: 1.07,2.38))$ and risk of RA. Compared to never smokers, the risk was still significantly elevated 15 years after smoking cessation ( $R R=1.99(95 \% \mathrm{Cl}: 1.23,3.20)$ ). However, among former smokers, the risk of RA seemed to be decreasing over time since stopping smoking: women who stopped smoking 15 years before the start of the follow-up had 30\% lower risk of RA compared to those who stopped only a year before start of the follow-up (RR $=0.70$ (95\% Cl: 0.24,2.02)).

Conclusions: This prospective study highlights that even light cigarette smoking is associated with increased risk of RA in women and that smoking cessation may reduce, though not remove, this risk.

\section{Introduction}

A large number of case-control studies [1-15] and fewer cohort studies [16-21] have shown that cigarette smoking is directly associated with the risk of developing rheumatoid arthritis (RA). Previous studies have mainly focused on establishing this association and assessed smoking status (current, former, and never smoker) [1,4,7,9,10,14-20] and pack-years of smoking [2,3,5,6,11-13,18,19], while less attention was given specifically to intensity $[6,8,16,18,20,21]$ and/or duration of smoking $[6,18,21]$. Results on these aspects of cigarette smoking have so far indicated that the risk of developing RA increases in a dose-response manner with the intensity and the duration of smoking. From a public health risk assessment perspective, however, it is also important to understand how much smoking is needed to increase the risk. Indeed, experimental data suggest that even a small

\footnotetext{
* Correspondence: daniela.digiuseppe@ki.se

'Division of Nutritional Epidemiology, Institute of Environmental Medicine,

Karolinska Institutet, Nobels vag 13, Stockholm, 171 77, Sweden

Full list of author information is available at the end of the article
}

amount of smoke exposure may trigger an immune reaction leading to development of RA [22,23] and therefore, even light smoking is theoretically enough to induce RA.

Even less is known about the effect of smoking cessation on future risk of RA. Indeed, only one case-control study [6] and two prospective cohort studies $[18,19]$ have evaluated the influence of smoking cessation on the risk of developing RA. Those results showed a decrease in risk 10 to 20 years after smoking cessation.

The aims of this study were therefore to further investigate if even light smoking is associated with increased risk of RA, and whether and to what extent smoking cessation may reduce the elevated risk of RA development among smokers. To this end, we analyzed the association between smoking (intensity, duration, pack-years) and smoking cessation and risk of RA in a prospective population-based cohort study of 34,101 women aged 54 to 89 years. 


\section{Materials and methods Study population}

The Swedish Mammography Cohort is a prospective cohort study established between 1987 and 1990. All women born between 1914 and 1948 and residing in two Swedish counties (Uppsala and Västmanland) received a questionnaire on diet and lifestyle. The response rate was $74 \%(n=66,651)$. In 1997 a second questionnaire was sent to women still alive with additional questions on smoking history, physical activity, use of some medications, and dietary supplements. The response rate was $70 \%$. Of the 39,227 questionnaires received, $243(0.6 \%)$ were excluded due to incorrect or missing personal identification numbers. For the purpose of the present study, we excluded women with missing values on smoking status $(n=797)$ and women with non-RA joint conditions ( $n=2,052$, ICD-10 codes M07 to M12, M14, M45, M46, M30 to M36). We also excluded women with a diagnosis of RA ( $n=432$, ICD-10 codes M05 and M06) or who died (1,602 women identified through the Swedish Death Register) before the start of follow-up on 1 January 2003.

The final study cohort included 34,101 women aged 54 to 89 years at the start of follow-up on 1 January 2003. This study was approved by the Regional Research Ethics Board at Karolinska Institutet, and all participants gave their informed consent.

\section{Assessment of smoking and covariates}

We used data from the 1997 questionnaire as the baseline, since smoking information was not collected in the 1987 questionnaire. Women were asked about smoking status, average number of cigarettes smoked per day at different ages ( 15 to 20,21 to 30,31 to 40,41 to 50 , and 51 to 60 years of age, and in the present year), age of starting smoking, and years since stopping smoking. Based on the data collected, we calculated the average number of cigarettes smoked per day during the smoking period (intensity) and the years of the period of smoking (duration), for both former and current smokers. Lifetime exposure to smoking was estimated by multiplying the average number of cigarettes smoked per day by the number of years the person had smoked divided by 20 (pack-years). For smoking cessation, the number of years since quitting smoking and the age at smoking cessation were calculated.

Intensity and duration were categorized according to tertiles of the distributions, while pack-years were categorized according to quartiles. Body mass index (BMI) was defined as weight in kilograms divided by the square of height in meters $\left(\mathrm{kg} / \mathrm{m}^{2}\right)$.

\section{Identification of RA cases and follow-up of the cohort}

Cases of RA were identified by linking the cohort to three Swedish registers, using the unique Swedish personal identification number. The Outpatient Register (OPR) of the Swedish National Board of Health and Welfare (NBHW) started in 2001 to collect information on outpatient visits including both public and private care-givers. The Swedish Rheumatology Register (SRR) is a webbased national surveillance system started in the midnineties as part of standard health care. The Inpatient Register (IPR) of the NBHW collects information on hospitalizations with national coverage from 1987. Data from IPR was used only to identify prevalent cases at the start of follow-up. Based on chart reviews, approximately $90 \%$ of the register-identified cases with RA fulfilled the American College of Rheumatology criteria [24,25].

We analyzed the distribution of the annual number of newly diagnosed RA patients in the OPR (Additional file 1) and we observed the presence of a mixture of prevalent and incident cases during the first years of the OPR. We therefore decided to introduce a 2-year lag period and delay the start of the follow-up to 1 January 2003. The follow-up period ended on 31 December 2010. In sensitivity analyses, alternative lag periods (3- and 5-year) were employed, and newly diagnosed RA cases identified during the follow-up period through the IPR were included (Additional file 1).

\section{Statistical analysis}

We used the Cox proportional hazard model to estimate the association between cigarette smoking and RA in terms of relative risk (RR) as the hazard rate ratio and its 95\% CI. All RRs had age as the time scale [26,27]. Additional adjustment was done for potential RA risk factors such as menopausal status (pre- or postmenopausal), parity $(0,1,2$, or $\geq 3$ children), use of alcohol (never, former, current $<2$ drinks per week, or $\geq 2$ drinks per week), educational level (lower than high school, high school, or university), and BMI (quartiles). To disentangle an independent effect of both years since quitting smoking and age at quitting smoking from the lifelong accumulated amount of smoking, the RR estimates were additionally adjusted for pack-years. Tests for trend were performed using the median value of each category to create a single continuous variable. We checked the proportionality of hazard over time using Schoenfeld's residuals [28]. There was no evidence of departure from the proportionality assumption. The dose-response association between years since quitting smoking and RA was further evaluated using the restricted cubic spline analysis [29].

A series of sensitivity analyses were performed to evaluate the consistency of the obtained results. First, we further delayed the start of the follow-up and we considered the inclusion as incident cases of newly diagnosed RA patients identified using hospitalization data from the IPR (Additional file 1, part A). Second, we performed a probabilistic sensitivity analysis, assuming that among 
newly diagnosed RA patients there are 0 to $20 \%$ prevalent RA cases. We made two assumptions regarding the smoking behavior of prevalent cases: no change in behavior, and smoking cessation (Additional file 1, part B).

We used SAS (version 9.2) to perform all the analyses, except for the restricted cubic spline analysis, which was performed in Stata (version 11.1). $P$-values lower than 0.05 were considered statistically significant.

\section{Results}

According to the main case definition 219 cases of RA were identified during the 8-year period of follow-up (254,996 person-years). Of these, 79 (36\%) were never smokers, 60 (27\%) were former smokers and the remaining $80(37 \%)$ cases were current smokers (Table 1). Former and current smokers were generally younger and were drinking more alcohol compared to never smokers. Intensity of smoking was similar among current and former smokers, while the duration of smoking was almost double among current smokers (mean $39 \pm$ SD 8.6 vs $22 \pm$ 12 years among former smokers).

Association between smoking and RA: intensity, duration, and pack-years

The age-adjusted RR of developing RA was 2.24 (95\% CI $1.63,3.07)$ among current smokers compared with never smokers, and was little influenced by further adjustment for menopausal status, parity, alcohol use, educational level, and BMI (multivariable adjusted RR = 2.20 (95\% CI 1.58, 3.04)) (Table 2). Among former smokers the multivariable adjusted risk of developing RA was $68 \%$ higher (95\% CI 19\%, 138\%) compared to never smokers.

Focusing on the intensity of cigarette smoking, measured as the lifetime average number of cigarettes smoked per day, we estimated that the risk of RA was more than twice the risk of never smokers, in both ageand multivariable-adjusted models, even for women with low intensity of smoking, that is, those who smoked 1 to 7 cigarettes per day. Regarding the duration of cigarette smoking evaluated among ever smokers, the multivariable risk for those who smoked for longer than 25 years was twice that of never smokers. The risk of developing RA among women who had smoked 1 to 5 pack-years was already $70 \%$ higher than the risk for never smokers.

We then analyzed the combined effect of intensity and duration of cigarette smoking (Table 3). Duration of smoking seemed to be a more important risk factor than smoking intensity. Light smokers (1 to 10 cigarettes per day) who smoked for many years (> 30 years) had a substantially elevated risk $(\mathrm{RR}=2.54,95 \% \mathrm{CI}$ 1.76, 3.69).

\section{Relative risk of RA following smoking cessation}

The effect of smoking cessation on the risk of RA was evaluated among former smokers, with attention to the number of years since quitting smoking and to the age at smoking cessation. There was a suggestion that the risk of RA was decreasing with years since quitting smoking, although the decrease was not statistically significant (Figure 1). Those who stopped smoking 15 years before baseline in 1997 had 30\% lower risk of RA compared to those who stopped only a year before, but the result was not statistically significant $(\mathrm{RR}=0.70,95 \% \mathrm{CI} 0.24,2.02)$.

However, compared to never smokers, the risk among those who stopped smoking more than 15 years before the start of follow-up was statistically significantly higher $(\mathrm{RR}=1.99,95 \%$ CI $1.23,3.20)$ (Table 4$)$. The risk of RA remained significantly elevated among those who stopped smoking at an early age: among those who stopped before the age of 41 years the risk was 2 -fold the risk of never smokers.

\section{Sensitivity analysis}

Results from the sensitivity analyses performed using four additional RA case definitions, as well as results from the probabilistic sensitivity analysis, were concordant with results from the main analysis (Additional file 1, Table A and B).

Table 1 Baseline characteristics by smoking status of 34,101 women from the Swedish Mammography Cohort, 1997

\begin{tabular}{|c|c|c|c|}
\hline & $\begin{array}{c}\text { Never smokers } \\
n=18,424(54 \%)\end{array}$ & $\begin{array}{l}\text { Former smokers } \\
n=7,817(23 \%)\end{array}$ & $\begin{array}{l}\text { Current smokers } \\
n=7,806(23 \%)\end{array}$ \\
\hline RA cases, number & 79 & 60 & 80 \\
\hline Age, years, mean (SD) & $63.6(9.2)$ & $58.9(8.2)$ & $58.9(8.2)$ \\
\hline Body mass index, $\mathrm{Kg} / \mathrm{m}^{2}$, mean (SD) & $25.2(3.8)$ & $25.2(4)$ & $24.4(3.9)$ \\
\hline Age of starting smoking, years, mean (SD) & & $19.5(5.8)$ & $20.2(6.9)$ \\
\hline Age at stopping smoking, years, mean (SD) & & $41.4(12.5)$ & \\
\hline Postmenopausal, \% & 83.9 & 72.3 & 77 \\
\hline Post-secondary education, \% & 17.3 & 24.8 & 17.2 \\
\hline Nulliparous, \% & 10.2 & 8.6 & 8.5 \\
\hline Alcohol users, \% & 76.2 & 92.5 & 91.2 \\
\hline
\end{tabular}

$R A$, rheumatoid arthritis. 
Table 2 Relative risk of rheumatoid arthritis by smoking status, intensity, duration and pack-years of cigarette smoking among (ever smokers) in the Swedish Mammography Cohort, 2003 to 2010

\begin{tabular}{|c|c|c|c|c|c|c|}
\hline & Person-years $^{1}$ & Cases, number $^{1}$ & Age-adjusted relative risk & $95 \% \mathrm{Cl}$ & Multivariable relative risk $^{3}$ & $95 \% \mathrm{Cl}$ \\
\hline \multicolumn{7}{|l|}{ Smoking status } \\
\hline Never & 137,162 & 79 & 1.00 (ref) & & 1.00 (ref) & \\
\hline Former & 59,466 & 60 & 1.65 & $1.17,2.32$ & 1.68 & $1.19,2.38$ \\
\hline Current & 58,368 & 80 & 2.24 & $1.63,3.07$ & 2.20 & $1.58,3.04$ \\
\hline \multicolumn{7}{|c|}{ Intensity, cigarettes $/$ day $^{2}$} \\
\hline Never & 137,162 & 79 & 1.00 (ref) & & 1.00 (ref) & \\
\hline 1 to 7 & 34,032 & 47 & 2.23 & $1.54,3.21$ & 2.31 & $1.59,3.36$ \\
\hline 8 to 14 & 32,010 & 45 & 2.23 & $1.54,3.24$ & 2.19 & $1.50,3.21$ \\
\hline$>14$ (median 18) & 35,586 & 33 & 1.45 & $0.96,2.20$ & 1.46 & $0.96,2.23$ \\
\hline \multicolumn{7}{|l|}{ Duration, years } \\
\hline Never & 137,162 & 79 & 1.00 (ref) & & 1.00 (ref) & \\
\hline 1 to 25 & 39,634 & 39 & 1.55 & $1.05,2.30$ & 1.60 & $1.07,2.38$ \\
\hline 25 to 40 & 53,219 & 68 & 2.01 & $1.43,2.83$ & 1.99 & $1.40,2.82$ \\
\hline$>40$ (median 45) & 23,528 & 32 & 2.36 & $1.55,3.58$ & 2.33 & $1.52,3.57$ \\
\hline \multicolumn{7}{|l|}{ Pack-years } \\
\hline Never & 137,162 & 79 & 1.00 (ref) & & 1.00 (ref) & \\
\hline 1 to 5 & 27,534 & 28 & 1.67 & $1.08,2.58$ & 1.72 & $1.11,2.67$ \\
\hline 6 to 13 & 30,613 & 40 & 2.13 & $1.45,3.13$ & 2.19 & $1.48,3.25$ \\
\hline 14 to 22 & 36,990 & 35 & 2.10 & $1.40,3.14$ & 2.04 & $1.35,3.09$ \\
\hline$>22$ (median 28) & 27,628 & 31 & 1.81 & $1.19,2.76$ & 1.82 & $1.19,2.79$ \\
\hline
\end{tabular}

${ }^{1}$ Numbers do not add up to the totals because of missing values; ${ }^{2}$ lifetime average among ever smokers; ${ }^{3}$ Adjusted for age (continuous), menopause status (preor postmenopausal), parity (0,1,2, or $\geq 3$ children), alcohol use (none, former, or current), educational level (lower than high school, high school, or university), and body mass index (quartiles). Intensity, duration and pack-years were not mutually adjusted [35]. Ref, reference group.

\section{Discussion}

In this population-based prospective study we observed an increased risk of RA for low levels of intensity, duration and pack-years of cigarette smoking. There was a suggestion that stopping smoking reduced the risk of RA over time among former smokers. However, compared to never smokers, the risk was still significantly elevated even among those who stopped smoking more than 15 years before the start of follow-up, and also among those who stopped smoking before age 41 years.

Our results are in agreement with a meta-analysis of smoking status [30], but some previous prospective studies found no statistically significant association between smoking and RA among current $[16,20]$ and former $[16,19,20]$ female smokers.
Previous studies have shown a dose response relationship between RA and smoking intensity $[6,18,21]$, duration $[6,18,21]$ and pack-years $[2,6,9,11,14]$, and with low levels of smoking, which were not statistically significantly associated with RA. Our results, showing a statistically significant increased risk even for light smokers, are instead in agreement with a previous case-control study of pack-years [5] and results from a retrospective study on duration of smoking [21]. Moreover, our finding that smoking duration has a stronger impact on RA development compared to smoking intensity was in accordance with the only previous study that evaluated those aspects of smoking in the same analysis [21].

Smoking cessation has been investigated in two prospective cohorts $[18,19]$ and one case-control study [6].

Table 3 Multivariable adjusted relative risk and $95 \%$ confidence interval for rheumatoid arthritis by intensity and duration of cigarette smoking in the Swedish Mammography Cohort, 2003 to 2008

\begin{tabular}{|c|c|c|c|c|c|c|}
\hline & \multirow[b]{2}{*}{ Cases, number } & \multirow[b]{2}{*}{$\begin{array}{l}\text { Never } \\
\text { smokers }\end{array}$} & \multicolumn{4}{|c|}{ Intensity } \\
\hline & & & Cases, number & $\begin{array}{c}1 \text { to } 10 \\
\text { Cigarettes/day }\end{array}$ & Cases, number & $\begin{array}{c}>10 \\
\text { Cigarettes/day }\end{array}$ \\
\hline \multicolumn{7}{|l|}{ Duration } \\
\hline Never smokers & 79 & 1.00 (ref) & & - & & - \\
\hline 1 to 30 years (median 17) & & - & 38 & $1.96(1.31,2.93)$ & 11 & $1.12(0.59,2.14)$ \\
\hline > 30 years (median 38) & & - & 51 & $2.54(1.76,3.69)$ & 25 & $1.56(0.98,2.50)$ \\
\hline
\end{tabular}

Results are presented as relative risk $(95 \% \mathrm{Cl}$ ) adjusted for age (continuous), menopausal status (pre-or postmenopausal), parity $(0,1,2$, or $\geq 3$ children), alcohol use (none, former, or current), educational level (lower than high school, high school, or university), and body mass index (quartiles). Ref, reference group. 


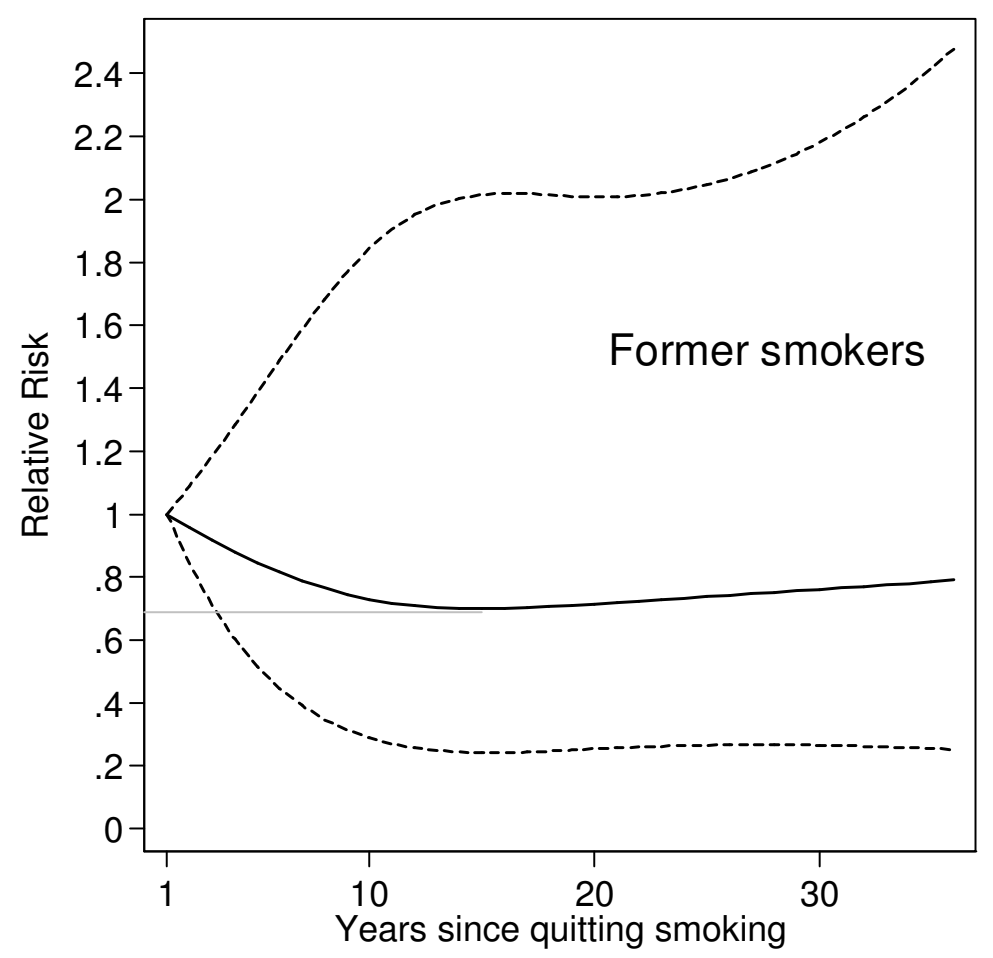

Figure 1 Relative risk estimation with $95 \%$ confidence interval for the association between rheumatoid arthritis (RA) and years since stopping smoking among former smokers. Model was adjusted for age (continuous), menopausal status (pre- or postmenopausaul), parity (0, 1,2 , or $\geq 3$ children), alcohol use (none, former, or current), educational level (lower than high school, high school, or university), BMI (quartiles) and pack-years of smoking (continuous among former smokers).

Our results, showing a statistically significantly increased risk even more than 15 years after smoking cessation, are not in agreement with these previous studies. Criswell et al. [19] and Stolt et al. [6] reported that the risk remained significantly elevated only for those who stopped smoking less than 10 years before baseline, but those studies did not take into consideration the possible confounding due to the pack-years of smoking. Costenbader et al. [18] showed that the risk was not statistically significant only among those who stopped smoking more than 20 years before baseline. Those results were adjusted for smoking intensity, while in the present study we preferred to adjust for pack-years, in order to take into account both duration and intensity of smoking. None of the previous studies examined the association between the age at stopping smoking and risk of RA.

The biological role of smoking in the development of RA is still unclear. However, it is known that smoking has many effects on the immune system [31,32]. In particular, smoking is a trigger for an immune response against citrullinated self-proteins, especially in the presence of $H L A-D R$ shared epitope genes [22,23], which in turn might cause arthritis $[4,5,33]$. Our results support

Table 4 Relative risk of rheumatoid arthritis among former smokers by years since quitting and age at quitting cigarette smoking in the Swedish Mammography Cohort, 2003 to 2010

\begin{tabular}{|c|c|c|c|c|c|c|}
\hline & Person-years $^{1}$ & Cases, number ${ }^{1}$ & Age-adjusted relative risk & $95 \% \mathrm{Cl}$ & Multivariable relative risk $^{2}$ & $95 \% \mathrm{Cl}$ \\
\hline Never smokers & 137,162 & 79 & 1.00 (ref) & & 1.00 (ref) & \\
\hline \multicolumn{7}{|c|}{ Years since quitting } \\
\hline $1-14$ & 23,297 & 20 & 1.45 & $0.88,2.38$ & 1.50 & $0.68,3.30$ \\
\hline$\geq 15$ (median 24) & 35,613 & 39 & 1.85 & $1.25,2.73$ & 1.99 & $1.23,3.20$ \\
\hline \multicolumn{7}{|l|}{ Age at quitting } \\
\hline$\leq 41$ (median 32) & 31,164 & 31 & 1.68 & $1.09,2.59$ & 1.94 & $1.18,3.18$ \\
\hline$>41$ (median 50) & 27,747 & 28 & 1.70 & $1.11,2.62$ & 2.02 & $1.01,4.07$ \\
\hline
\end{tabular}

${ }^{1}$ Numbers do not add up to the totals because of missing values. ${ }^{2}$ Adjusted for age (continuous), menopausal status (pre- or postmenopausal), parity (0, 1,2 , or $\geq 3$ children), alcohol use(none, former, or current), educational level (lower than high school, high school, or university), body mass index (quartiles), and packyears of smoking (continuous among former smokers). Ref, reference group. 
this biological explanation since even a relatively low amount of total smoking ( 1 to 5 pack-years) was associated with an almost double risk of RA. Moreover, the triggering mechanism is also in line with our results on the lack of decrease in risk after smoking cessation compared to never smoking.

The strength of this study is its prospective population-based design in which the ascertainment of exposure was independent of the ascertainment of outcome. Self-reported smoking status was validated in previous papers against cotinine-plasma levels and found to be accurate [34].

To identify newly diagnosed cases of RA during the follow-up period we used two Swedish registers, while some previous studies $[16,18,19,21]$ used self-reported and subsequently validated RA diagnosis. However, the use of registers requires some attention, since the date of first diagnosis in the register does not always correspond to the onset of disease. The SRR, which has more accurate information on the date of onset of the disease, did not have complete coverage in the study area, and therefore it was not possible to use it as the only source of information on new RA cases. Additionally, data from the OPR was only available from 2001 . We decided to start the follow-up period two years later in 2003, since we noticed an excess in the number of newly diagnosed RA patients in these years (Additional file 1, Figure App-1). This phenomenon can be explained by the presence of patients who appeared for the first time in the register but had already a previous diagnosis of RA. Another possible source of data for newly diagnosed RA cases is the IPR. However, we considered newly diagnosed RA cases identified through hospitalization as prevalent cases, and therefore we excluded them from the cohort, since RA is a disease that usually does not lead to hospitalization in the first stages. Since this assumption could be considered too strict, we considered the inclusion of these cases in sensitivity analyses (Additional file 1, part A). Results of the sensitivity analyses were consistent with observed results in the main analysis.

The gap between data collection and the start of followup could be considered a strength of this study. Since the onset of RA cannot usually be considered to concurring with the diagnosis date, there is the possibility that people with early symptoms of RA change their habits, leading to differential misclassification. This could explain why the increased risk among women in the higher category of intensity of smoking was only borderline statistically significant. However, an early assessment of exposure and covariates in our study 6 years before the start of followup should help prevent this misclassification.

Among the limitations of this study, is the fact that we only have data on women aged 54 to 89 years, and so we were unable to assess the risk of RA among younger women and men. Moreover, the number of individuals who quitted smoking was fairly limited, leading to problems of power in the estimates. Information about smoking habits was collected only to a single occasion (1997), whereas repeated measures during the study period could have been more appropriate to avoid possible non-differential misclassification of the exposure. Stratification by presence of rheumatoid factor was not possible in this study due to lack of complete information from the registers and limited statistical power. Furthermore, we had not information about shared-epitope genes. It would have been of great interest to perform such stratified analyses since evidence is growing of a greater risk of RA related to cigarette smoking when in interaction with $H L A-D R$ shared-epitope genes [4,5,11].

\section{Conclusions}

In conclusion, our study indicated that even light smoking is associated with increased risk of RA for women. In extension to this, we showed that the risk of RA was decreasing over time after smoking cessation, but compared to never smokers the risk was still statistically significantly higher. The clearly increased risk of RA development even among former smokers is another reason to persuade women not to start smoking.

\section{Additional material}

Additional file 1: Sensitivity analyses. A series of sensitivity analyses were performed to evaluate the consistency of the reported results. In part $A$, different case definitions were considered. In part B, a probabilistic sensitivity analysis was performed by excluding possible prevalent cases included in the study as incident cases.

\section{Abbreviations}

BMl: body mass index; IPR: Inpatient Register; OPR: Outpatient Register; RA: rheumatoid arthritis; RR: relative risk; SRR: Swedish Rheumatology Register.

\section{Authors' contributions}

DDG, NO, LA, JA, and AW participated in the study design and in writing the manuscript. DDG, NO and AW participated in the data collection. DDG analyzed the data and wrote the manuscript under the supervision of AW. DDG, NO, LA, MB, JA, and AW interpreted the data and critically reviewed the paper. All authors read and approved the final manuscript.

\section{Competing interests}

The authors declare that they have no competing interests.

\section{Acknowledgements}

This work was supported by research grants from the Swedish Research Council/Committee for Medicine, from the Swedish Research Council/ Committee for Research Infrastructure for maintenance of the Swedish Mammography Cohort, from the Swedish COMBINE inflammation research consortium. Ms Di Giuseppe was supported by the Karolinska Institutet's Award for PhD students.

\section{Author details}

${ }^{1}$ Division of Nutritional Epidemiology, Institute of Environmental Medicine, Karolinska Institutet, Nobels vag 13, Stockholm, 171 77, Sweden. ${ }^{2}$ Division of 
Cardiovascular Epidemiology, Institute of Environmental Medicine, Karolinska Institutet, Nobels vag 13, Stockholm, 171 77, Sweden. ${ }^{3}$ Clinical Epidemiology Unit, Department of Medicine, Rheumatology Unit d2:01, Karolinska University Hospital, Solna, 171 76, Sweden.

Received: 21 November 2012 Revised: 31 January 2013 Accepted: 12 March 2013 Published: 22 April 2013

\section{References}

1. Criswell LA, Saag KG, Mikuls TR, Cerhan JR, Merlino LA, Lum RF, Pfeiffer KA, Woehl B, Seldin MF: Smoking interacts with genetic risk factors in the development of rheumatoid arthritis among older Caucasian women. Ann Rheum Dis 2006, 65:1163-1167.

2. Hutchinson D, Shepstone L, Moots R, Lear JT, Lynch MP: Heavy cigarette smoking is strongly associated with rheumatoid arthritis (RA) particularly in patients without a family history of RA. Ann Rheum Dis 2001, 60:223-227.

3. Olsson AR, Skogh T, Wingren G: Comorbidity and lifestyle, reproductive factors, and environmental exposures associated with rheumatoid arthritis. Ann Rheum Dis 2001, 60:934-939.

4. Padyukov L, Silva C, Stolt P, Alfredsson L, Klareskog L: A gene-environment interaction between smoking and shared epitope genes in HLA-DR provides a high risk of seropositive rheumatoid arthritis. Arthritis Rheum 2004, 50:3085-3092.

5. Pedersen $M$, Jacobsen $S$, Klarlund $M$, Pedersen BV, Wiik A, Wohlfahrt J, Frisch M: Environmental risk factors differ between rheumatoid arthritis with and without auto-antibodies against cyclic citrullinated peptides. Arthritis Res Ther 2006, 8:R133.

6. Stolt P, Bengtsson C, Nordmark B, Lindblad S, Lundberg I, Klareskog L, Alfredsson $L$ : Quantification of the influence of cigarette smoking on rheumatoid arthritis: results from a population based case-control study, using incident cases. Ann Rheum Dis 2003, 62:835-841

7. Uhlig T, Hagen KB, Kvien TK: Current tobacco smoking, formal education, and the risk of rheumatoid arthritis. J Rheumatol 1999, 26:47-54.

8. Hazes JM, Dijkmans BA, Vandenbroucke JP, de Vries RR, Cats A: Lifestyle and the risk of rheumatoid arthritis: cigarette smoking and alcohol consumption. Ann Rheum Dis 1990, 49:980-982.

9. Kallberg H, Ding B, Padyukov L, Bengtsson C, Ronnelid J, Klareskog L, Alfredsson $\mathrm{L}$ : Smoking is a major preventable risk factor for rheumatoid arthritis: estimations of risks after various exposures to cigarette smoke. Ann Rheum Dis 2011, 70:508-511.

10. Krishnan E, Sokka T, Hannonen P: Smoking-gender interaction and risk for rheumatoid arthritis. Arthritis Res Ther 2003, 5:R158-162.

11. Mikuls TR, Sayles H, Yu F, Levan T, Gould KA, Thiele GM, Conn DL, Jonas BL, Callahan LF, Smith E, Brasington R, Moreland LW, Reynolds RJ, Bridges SL Jr: Associations of cigarette smoking with rheumatoid arthritis in African Americans. Arthritis Rheum 2010, 62:3560-3568.

12. Too CL, Yahya A, Murad S, Dhaliwal JS, Larsson PT, Muhamad NA Abdullah NA, Mustafa AN, Klareskog L, Alfredsson L, Padyukov L, Bengtsson C, MyEIRA study group: Smoking interacts with HLA-DRB1 shared epitope in the development of anti-citrullinated protein antibody-positive rheumatoid arthritis: results from the Malaysian Epidemiological Investigation of Rheumatoid Arthritis (MyEIRA). Arthritis Res Ther 2012, 14:R89.

13. Voigt LF, Koepsell TD, Nelson JL, Dugowson CE, Daling JR: Smoking, obesity, alcohol consumption, and the risk of rheumatoid arthritis. Epidemiology 1994, 5:525-532.

14. Yahya A, Bengtsson C, Lai TC, Larsson PT, Mustafa AN, Abdullah NA, Muhamad N, Hussein H, Klareskog L, Alfredsson L, Murad S: Smoking is associated with an increased risk of developing ACPA-positive but not ACPA-negative rheumatoid arthritis in Asian populations: evidence from the Malaysian MyEIRA case-control study. Mod Rheumatol 2012, 22:524-531.

15. Symmons DP, Bankhead CR, Harrison BJ, Brennan P, Barrett EM, Scott DG, Silman AJ: Blood transfusion, smoking, and obesity as risk factors for the development of rheumatoid arthritis: results from a primary care-based incident case-control study in Norfolk, England. Arthritis Rheum 1997, 40:1955-1961.

16. Avila MH, Liang MH, Willett WC, Stampfer MJ, Colditz GA, Rosner B, Roberts WN, Hennekens CH, Speizer FE: Reproductive factors, smoking, and the risk for rheumatoid arthritis. Epidemiology 1990, 1:285-291.
17. Carlens C, Hergens MP, Grunewald J, Ekbom A, Eklund A, Hoglund CO, Askling J: Smoking, use of moist snuff, and risk of chronic inflammatory diseases. Am J Respir Crit Care Med 2010, 181:1217-1222.

18. Costenbader KH, Feskanich D, Mandl LA, Karlson EW: Smoking intensity, duration, and cessation, and the risk of rheumatoid arthritis in women. Am J Med 2006, 119:503 e501-509.

19. Criswell LA, Merlino LA, Cerhan JR, Mikuls TR, Mudano AS, Burma M, Folsom AR, Saag KG: Cigarette smoking and the risk of rheumatoid arthritis among postmenopausal women: results from the lowa Women's Health Study. Am J Med 2002, 112:465-471.

20. Heliovaara M, Aho K, Aromaa A, Knekt P, Reunanen A: Smoking and risk of rheumatoid arthritis. J Rheumatol 1993, 20:1830-1835.

21. Karlson EW, Lee IM, Cook NR, Manson JE, Buring JE, Hennekens CH: A retrospective cohort study of cigarette smoking and risk of rheumatoid arthritis in female health professionals. Arthritis Rheum 1999, 42:910-917.

22. Klareskog L, Padyukov L, Alfredsson L: Smoking as a trigger for inflammatory rheumatic diseases. Curr Opin Rheumatol 2007, 19:49-54.

23. Klareskog L, Stolt P, Lundberg K, Källberg H, Bengtsson C, Grunewald J, Rönnelid J, Harris HE, Ulfgren AK, Rantapää-Dahlqvist S, Eklund A, Padyukov $L$, Alfredsson $L$ : A new model for an etiology of rheumatoid arthritis: smoking may trigger HLA-DR (shared epitope)-restricted immune reactions to autoantigens modified by citrullination. Arthritis Rheum 2006, 54:38-46.

24. Baecklund E, lliadou A, Askling J, Ekbom A, Backlin C, Granath F, Catrina Al, Rosenquist R, Feltelius N, Sundström C, Klareskog L: Association of chronic inflammation, not its treatment, with increased lymphoma risk in rheumatoid arthritis. Arthritis Rheum 2006, 54:692-701.

25. Knight A, Sandin S, Askling J: Increased risk of autoimmune disease in families with Wegener's granulomatosis. J Rheumatol 2010, 37:2553-2558.

26. Korn EL, Graubard Bl, Midthune D: Time-to-event analysis of longitudinal follow-up of a survey: choice of the time-scale. Am J Epidemiol 1997, $145: 72-80$

27. Thiebaut A, Benichou J: Choice of time-scale in Cox's model analysis of epidemiologic cohort data: a simulation study. Stat Med 2004 23:3803-3820.

28. Schoenfeld D: Partial residuals for the proportional hazards regression model. Biometrika 1982, 69:239-241.

29. Harrell FEJ, Lee KL, Pollock BG: Regression models in clinical studies: determining relationships between predictors and response. J Natl Cancer Inst 1988, 80:1198-1202.

30. Sugiyama D, Nishimura K, Tamaki K, Tsuji G, Nakazawa T, Morinobu A, Kumagai S: Impact of smoking as a risk factor for developing rheumatoid arthritis: a meta-analysis of observational studies. Ann Rheum Dis 2010, 69:70-81.

31. Stämpfli MR, Anderson GP: How cigarette smoke skews immune responses to promote infection, lung disease and cancer. Nat Rev Immunol 2009, 9:377-38.

32. Domagala-Kulawik J: Effects of cigarette smoke on the lung and systemic immunity. J Physiol Pharamacol 2008, 59:19-34

33. Kuhn KA, Kulik L, Tomooka B, Braschler KJ, Arend WP, Robinson WH, Holers VM: Antibodies against citrullinated proteins enhance tissue injury in experimental autoimmune arthritis. J Clin Invest 2006, 116:961-973.

34. Patrick DL, Cheadle A, Thompson DC, Diehr P, Koepsell T, Kinne S: The validity of self-reported smoking: a review and meta-analysis. Am J Public Health 1994, 84:1086-1093.

35. McKnight B, Cook LS, Weiss NS: Logistic regression analysis for more than one characteristic of exposure. Am J Epidemiol 1999, 149:984-992.

\section{doi:10.1186/ar4218}

Cite this article as: Giuseppe et al:: Cigarette smoking and smoking cessation in relation to risk of rheumatoid arthritis in women. Arthritis Research \& Therapy 2013 15:R56. 